\title{
Understanding Dimensioning of Knowledge Transfer Perspectives
}

\author{
Michael Fascia \\ College of Medicine, School of Clinical Science, University of Edinburgh, Scotland, UK
}

Received 5 April 2015, Accepted 4 May 2015

\begin{abstract}
:
Most current conceptualization of knowledge transfer emerges from the premise of occidental heritage. This paper examines the dialectical procedure, underpinning the unification of knowledge as an entity, and discusses dimensions of knowledge and knowledge transfer from the practitioner's perspective. The study asks why, if knowledge is vital for business success and competitive advantage, the transfer of knowledge is rarely a simple unproblematic event. Further, that the creation of knowledge before transfer is recognized within literature as a significant factor in determining a starting point for analogous scrutiny. The theoretical standpoint adopted in this study therefore, looks to synthesis from practical interaction and observation, epistemic principals of 'knowledge', which underpins knowledge transfer theories and perspectives from the point of view of Philosophical, Organizational, Psychological and Cultural boundaries. To do this, the study will examine knowledge transfer practices within a large retail environment. The study incorporated $(n=20)$ interviews in and around the workplace. Results indicated that whilst there was a degree of incredulity amongst the knowledge transfer practitioners, the main theme to emerge was that knowledge was less difficult to transfer if the interpretation and experiential relationships of the practitioners aligned to a similar perspective. Findings show that ideologies, especially those associated with religious beliefs, are used to establish successful trends in motivation, interaction, leadership and experience in a business context. This identification of factors and interactions contribute to a wider understanding of the relationship between success and knowledge transfer and thus allows boundaries and parameters to fortify a knowledge transfer arena from which to establish metrics. From this research, more detailed investigation will allow new conceptual models to be considered and existing theoretical models to be re-designed and re-positioned.
\end{abstract}

Keywords: Knowledge, Knowledge transfer, Culture, Religion, Perspective, Experience, Subjectivity

\section{INTRODUCTION}

This study focuses on the role of knowledge in an organizational environment and encompasses the dimension of culture, philosophy, and psychology. Since we already understand that knowledge transfer is rarely a simple unproblematic event (Argote et al., 2000) and much research and study has gone into understanding the mechanics of the transfer sequence to assist in eradicating the associated and even nefarious problems.

The understood topology and entity of
Knowledge can generally be regarded as falling between 2 arguments, the first is Rationalism, (Descartes, 1644; Leibniz, 1673; Kant, 1787) which postulates that a proposition can be known from reason alone without the need for or indeed independent from experience. The second is Empiricism (Aristotle; Berkeley, 1710; Hume, 1739), which postulates that propositions can only be known from experience. The creation of this knowledge before it is transferred, is significantly theorized by (Nonaka and Takeuchi

*Corresponding Author, Email:v1mfasci@staffmail.ed.ac.uk 
,1995) as a fundamental and important factor for any business or organization, as it will affect and influence the transfer process. Additionally, there is broad agreement, that the knowledge transfer is a process transpired between two units, and this interaction is; critical for an organization and is, in the main, problematic and difficult (Nonaka and Takeuchi, 1995). Complex (Liebowitz, 2002). Required to be group focused when useful as an asset, (Argote and Ingram, 2000). Assumed an increasingly legitimate and important role in organization science, (Nonaka and Krogh, 2009). From this broad base, this particular study will focus on a UK retail business. The business has been trading successfully for over 30 years, in which time it has never undertook a systematic analysis of business practices to evaluate efficiency or competitive advantage, SWAT for example, and theoretical modeling of current practices was unknown. Underpinning of this point of view is important since prominent authors, such as Barney (1991), Davenport and Prusak (1998), Brown and Duguid (1998: 2000: 2001) and practitioners, such as Argote and Ingram (2000), clarified the importance of interpretation of knowledge for an organization wishing to achieve a competitive advantage (Tallman et al., 2004).

\section{Synopsis}

This study asks two simple questions; Q1: does this business follow traditional business models to underpin success and competitive advantage, despite there being no evidence to suggest this. And Q2: is knowledge transfer able to be identified and encompass a measurement boundary. Accordingly, organizational dialog in this context highlights the importance in understanding epistemic principles evident in current theoretical interpretation surrounding knowledge in a business scenario.

\section{Literature Review}

In understanding the importance of the knowledge within an organization (Felin and Hesterly, 2007), how it is constructed (Nonaka, 1995: 2006) and subsequently transferred (Hansen et al., 2005), a complete procedural scenario must be first interpreted (Hansen, 2002) and then understood. It makes sense therefore, that it must be as important to understand the significance of experiential reasoning behind the interpretive position of all the actors involved. In this case, it remains important to distinguish between truth and perceived truth in the context of the knowledge to be transferred (Felin and Hesterly, 2007). For example, when conceiving as a faculty for distinguishing between truth and falsity, any judgement that lacks cognitive status ascribed them, will result in the interpretation of validity to be considered false (Blackburn, 1987). Consequently, without a conceptual understanding of knowledge, definition attributed to the success of a transfer mechanism or perspective of success, success cannot be easily established for the practitioner or observer (Dyer and Hatch, 2006). This is because, understanding of problematic transfer increases and decreases as interpretation moves from one philosophical understanding or viewpoint of knowledge and the other. For example, Metaphysical V Epistemological, and in doing so, making the definition of any perspective, successful or otherwise, complex and variable. That is to say, understanding of this position must be related to interceding anomalies or anticipated problems (Szulanski, 1996: 2004) within the practitioner's realm of understanding (Hansen, 2002). Therefore, only by analyzing the complete and complex knowledge transfer process can the association of any 'successful' interaction between knowledge transfer practitioners be identified.

\section{Positional Inferences}

To underline the interpretation of knowledge from the position of study, 'foundationalism' is used as an underpinning to any analysis and discussion attached to data interpretation (BonJour, 2003). Similarly, the study suggests that 'hermeneutics' (Audi 1999) would form part of the axiom for analysis. In adopting this position, most, if not all, continental philosophers would understandably agree that epistemological hermeneutics and foundationalism are not directly compatible. However, in the context of organizational knowledge and subsequent knowledge transfer scenarios in this study, the analytic and continental traditions may be closer than is commonly understood. That is to say, it is commonly agreed that foundationalism is a normative posit about how beliefs are related to 
one another (Klein, 1999), and hermeneutics, represents a descriptive posit about human cognition (Audi, 1999), it is evident that if the underpinning statements are presented correctly, disparity starts to reduce. On the one hand, foundationalism, at least in its generic form, can be understood as making one fundamental claim regarding the structure of belief. Thought about in this way, this synergy suggests that all the beliefs of a particular person will exhibit a certain structure, therefore, assumes validation in making a narrative claim regarding how beliefs ought to be inter related. On the other hand, hermeneutics can be used to describe the reference to a number of different and variegated theories, but with a commonality of interpretation. In this regards, claiming how someone really thinks in a descriptive form and therefore, most, if not all, knowledge claims are interpretive in character. For the purposes of this study, it follows therefore, that it would be plausible to understand abstract or contested parts of knowledge as valid, since in accepting a knowledge statement of fact, it is unimportant in deciding if it is a foundational ethic or not, based on the interpretation of its evidence. However, clearly at this point, we could ask if the existence of knowledge, which depends on the interpretation of a foundational normality is true, then, all knowledge must derive from a consequence of foundational ethics (Berkeley, 1710), which in themselves cannot be refuted by accepted moral norms. From this adaptive positioning, we in fact could argue that it is the complex interactions of, human nature, scientific parameters and empirical boundaries, which define knowledge entities. However, if this where the universally adopted view, it would consequently induce a notion that all knowledge is prescriptive instead of descriptive. It is clear however, that interpretive praxis for knowledge schema could be debated at length, as there is no such thing as 'normal knowledge'. Therefore, to gain a positional understanding, as an observer, we must examine how knowledge fits within an interpretive overview of a formalized description in a organizational context, and not how knowledge is defined by a description derived from experience.
Problems with Knowledge Transfer Legitimacy

Thus, if we advocate this axiom, we can simultaneously endorse both hermeneutics and foundationalism and therefore, can begin to approach epistemological issues surrounding knowledge transfer mechanisms (Brown and Duguid, 2001) from a pragmatic or neutral centre. Furthermore, when conceptualizing knowledge as a transferable entity in an organizational capacity (Felin and Hesterly, 2007), it is important to consider the different asymmetries within which human beings hold beliefs, basic and non-basic. Non-basic beliefs are based on other beliefs by interference, for example 'I believe that all green apples are sweet', is based on an inference that 'all apples are sweet'. Basic beliefs, are of course not. For example 'I believe that I am sitting in front of this computer, writing this paper', is based on my experience I am having right now, and not by inference of some other belief. Clearly, there is a fundamental problem in aligning these posits regarding their usefulness in conducting a study of this complexity (Mason, 2002). Since, previously discussed positional inferences, (hermeneutics and foundationalism) presuppose an assumption, in that, they both require associations regarding knowledge to be interpretable by all actors (Watson and Hewett, 2006) thus, senders, receivers and observers. Hence, they (hermeneutics and foundationalism) are inextricably linked to knowledge and knowledge transfer as a combined process or entity, (Mitton et al., 2007) however, perhaps not as traditional western philosophers would position it. In dealing with knowledge in this context, we can allow for an inference of an experience to be transferred as a non-valuable postulation, which becomes valuable irrespective of the success of the transfer (Szulanski, 2000). Therefore, in the context of this study, we use this eidetic reduction to highlight the essence of the proposition for the sender and define its best course of transfer based on a similar propositional stance for the recipient. In this schema, scepticism, materialism, and positivism (A) stand on the one hand, spiritualism, idealism, and theology (B) stand on the other (Jaw et al., 2007). From this perspective, narcissistic importance contributes to the 
construction of knowledge, deriving from a route of primarily cognitive processes and is a persuasion of a summary of both individual and collective reflection and reasoning (Polanyi, 1966). That is to say, as an observer, there would be a need to position ourselves in such a way as to develop an understanding of the experience that we are part of (Polanyi, 1962: 1964: 1967), since faith, order and optimism increase as we move from one adoptive position to another.

\section{Transfer Scenario}

Nonetheless, perceptual interrogation and conceptual thinking (Okhuysen and Eisenhardt, 2002) form an idealism into a metaphysical position which is distinctly difficult to ascertain. Similarly, as a useful tool for knowledge definition in this original context, or as an aphorism for efficient knowledge transfer analysis (Michailova and Hutchings, 2006). As indicated in figure 1, whilst there is an intention to transmit knowledge, there is no way to establish a route of transfer without establishing the boundary of travel first.

This asymmetry presents us with a fundamental problem when it comes to ascertaining if indeed we can offer a comprehensive analysis of the knowledge in the context of 'knowledge transfer' within this (or any other) organization. This is because, most management literature on the subject assumes a proposition from knowledge that it is true and in doing so, maintains a positivist interpretation of truth as the default state (Tsoukas and Vladimorou, 2001; Watson and Hewett, 2006).
Knowledge at the delineation point, must be an infallibility assumption, through an evidence based evaluation of its position in relation to either the transferor or the receiver of the knowledge (Reed and DeFillippi, 1990). If this was not the case, it is the experience of the knowledge which is transferred not the knowledge. Therefore, in accepting a position from which to postulate a defining paradigm for success, at this point one could ask, is it possible to extend our understanding of those abstract concepts? That is to say, to make these concepts themselves precise and to gain comprehensive and secure insight about the fundamental relationships that are present among them, moreover, the axioms that hold for them? Similarly, we could also ask, in what way would our everyday experiences be different, if they did not fit into this conclusion of mechanistic naturalism? Nothing, in fact would be notably different, material objects would still exist tables and chairs would still 'be', however they would not represent mind independent objects, since they would not exist in their own mind, only in someone (observers) else's. As such, knowledge from this perspective is non-reductive and nonspecific, in that, it can only exist because someone knows it in his mind, it is an empirical conception of experience. In this state, it is not an independent entity to be transferred, such as any material object might be. For example, the chair cannot be transferred as knowledge, it is not a knowledge, although clearly the constituent manufacturing process and incumbent costs which effect the organization are.
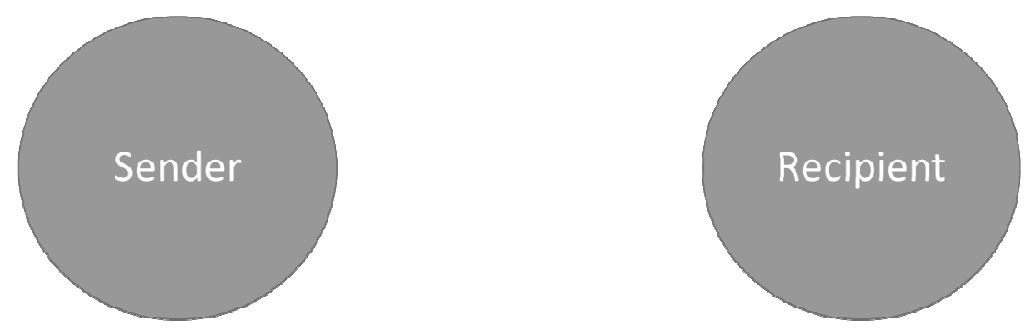

INTENDED ROUTE OF TRANFER

Figure 1: Intended transfer Scenario 


\section{Knowledge Route}

This important caveat is a core consideration for this study, as throughout the extended route of knowledge in an organisation (Schultze and Stabell, 2004), knowledge is regarded as invariable, singular, although ultimately significant as definitive state (Spender 1996). However, as the transfer parameters begin to adopt the focus of prioritised importance and become more relevant (Alvesson and Kärreman, 2001), the complicated social mechanisms for knowledge construction (Berger, 1966) are ignored in favour of the equally complex transfer mechanism (Dyer and Hatch, 2006). In doing so, two clarifications would be in order immediately. Firstly, this locus would give no positional clarification on whether or not justified foundational beliefs would interact or depend on anything else, for example experience for their justification. Second, the inferential epistemic dependence is a casual relation, in that, this would infer that knowledge does not entail any dependence on the source or recipient for anything. Since this possession of knowledge is in itself derived from a sequence of parameters which are classified from a position of truth and belief, and that the position of belief of the locus of the knowledge to be transferred must be true, then we can conclude that the theoretical origination of the knowledge to be transferred could be derived from these epistemological contexts. Thus, the conceptual ingredients or constituent parts of knowledge as we understand from this standpoint, form a philosophical perspective which ultimately defines propositional validity to the scenario being observed, irrespective of the validity of the knowledge. In this regards, figure 2 suggests therefore that within the transfer scenario, the intention to understand knowledge experience in its regressive and transient viewpoints is fundamental (Felin and Hesterly, 2007), that is, if participants can establish this, then they can assume a directly associated ontological point of view which by default will be contextually acceptable to all actors.

This means actors try to understand human experience from the point of view of the individual who is experiencing the knowledge transfer. From these observations, we can deduce that constituents of knowledge (Dyer and Hatch, 2006) are simply a collection of actual and possible human experiences, defined by a group of participating actors within a knowledge transfer scenario (Hansen, 2002: 2005).

Therefore, investigations must consider the individual from an outside point of view, as if it were an unprejudiced point of view. The observer, in this case is considered objective, as the observation by the observer corresponds to reality. Therefore, to fully understand this perspective, throughout this study we must first designate a contextual meaning to our understanding of 'knowledge', in that, what exactly gets transferred and which route does it need to achieve this. Figure 3 points to the fact that normally adopted assumption of a transfer route, given the establishment of knowledge as a contextual relationship to experience.

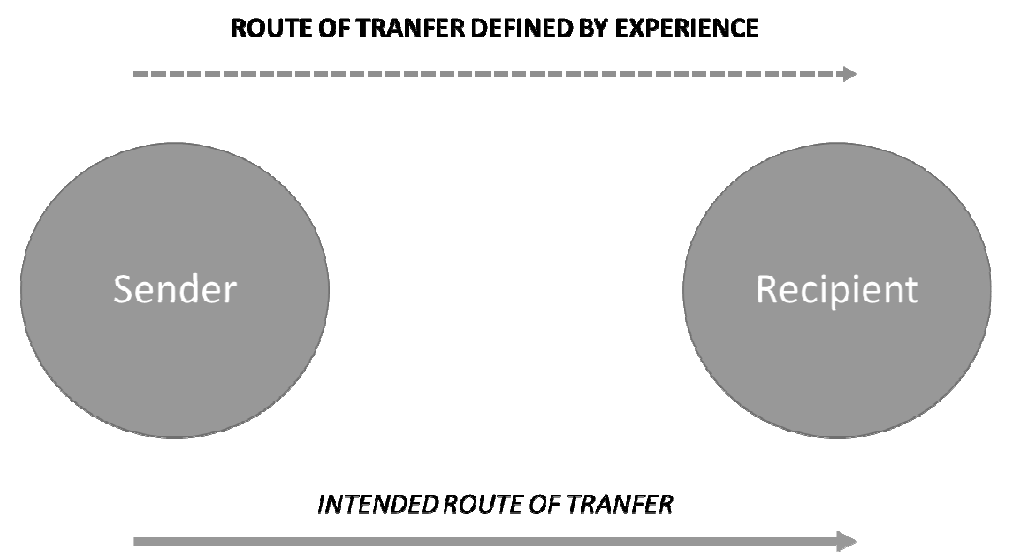

Figure 2: Route of knowledge defined by experiential proposition 


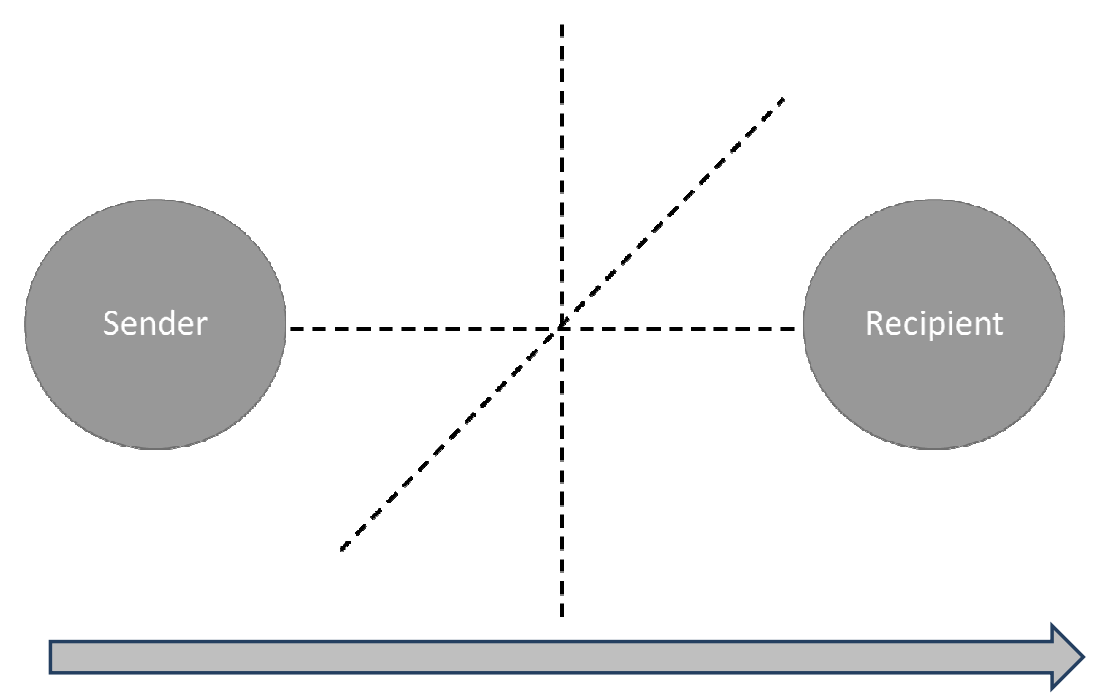

Figure 3: Assumed transfer scenario

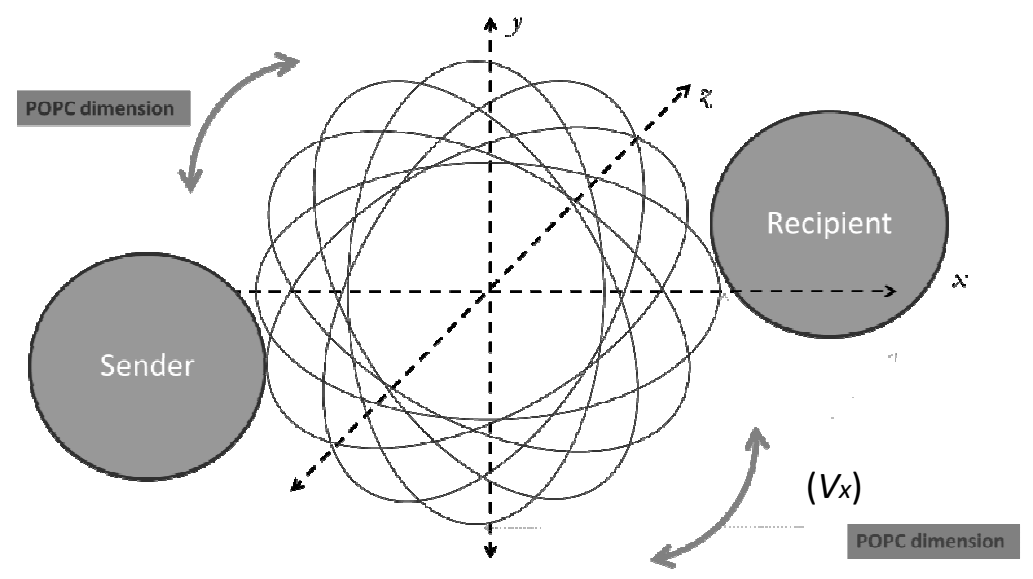

Figure 4: Transfer scenario determined by a POPC dimension

Consequently, without the prejudice of a dimensioning interpretation from the observer's point of view, it must be the experiential coherences to the constitutive experiential conditions of the participants which are transferred, because nothing else exists as knowledge transfer at this point, as there are no boundaries from which to contextually determine validity or measurement. In addition to this position, figure 4 indicates that investigations must accept that a level of complexity exists as a barrier to accurate assessment of this phenomena. Consequently, this study will introduce the notion of how a knowledge transfer scenario and the use of POPC (Psychological, Organizational, Philosophical, Cultural) as a dimensional lens, can be used to establish a point of contextual alignment, from which we can determine its (knowledge transfer scenario) boundaries and parameters. 
In positioning itself at this juncture, the research can align with a majority of current literature themes, centered on arguments, which support the notion of knowledge transfer processes (Watson and Hewett, 2006), and are embedded within a set of real world dimensions (Jensen and Szulanski, 2004; Nonaka et al., 2006). As such, this position can incorporate both causal relationships and intermediate experiences as a single strand or state of reference (Okhuysen and Eisenhardt, 2002). This locus is therefore a significant pivot for the study to adopt since current literature does not determine what, if any, dimension characteristics support group interaction or personal perspectives within a knowledge framework are which relationships are critical for transfer efficiency. Consequently, we can now attribute a relevant structure to this literature dimension thus, $\mathbf{P O P C}=\mathbf{V x}$

\section{RESEARCH METHOD}

This study is based on qualitative methodology because it follows an exploratory approach of a topic which is believed to be culturally sensitive (Berg, 1995). Similarly, an exploratory, interactive approach enabled the interviewees better to express their own perspective. The used a semi-structured interview guide adopting the qualitative research design proposed by Cresswell (2006).

Snowball sampling (Coleman, 1958) was used to determine and build the participant group. Interviews $(n=20)$ included pre-planned questions as well as open-ended questions which led into a conversation and gave the respondents the possibility to bring in examples and own experiences. In this way, a systemic archetype for research was accomplished by detailing a paradigm sequence of analysis from the interview analysis. Inevitably, this included an appreciation of philosophical positioning of the actors involved with knowledge transfer, and aligning this with a detailed review of the current management literature on the subject of knowledge transfer.

In as much as, the adaptation of the actors involved purport to a position of validity in the transfer schema, but of course, not withstanding any egoistic conceptions of this reality or cautious belief of any experience other than that relative to the knowledge transfer scenario. Since the understanding of knowledge will include many contexts, both holistic and flux-like, any study of these phenomena required a comprehensive review of management literature, both current and historical.

\section{RESULTS AND ANALYSIS}

The interviews were conducted over a period of 1 month (Fed) in 2015. Each interview lasted for 30 to 60 minutes. All interviews were taperecorded and field notes were taken. Content analysis was carried out to identify theoretical implications for developing propositions. Common themes were identified across cases in order to seek analytical generalization. This was achieved by analyzing the meanings individuals associate with knowledge transfer and experiential and interpretive meanings emerged as clusters throughout interviews and deduced from a weighted POPC (Psychological, Organizational, Philosophical, Cultural) dimension, as indicated in figure 5 .

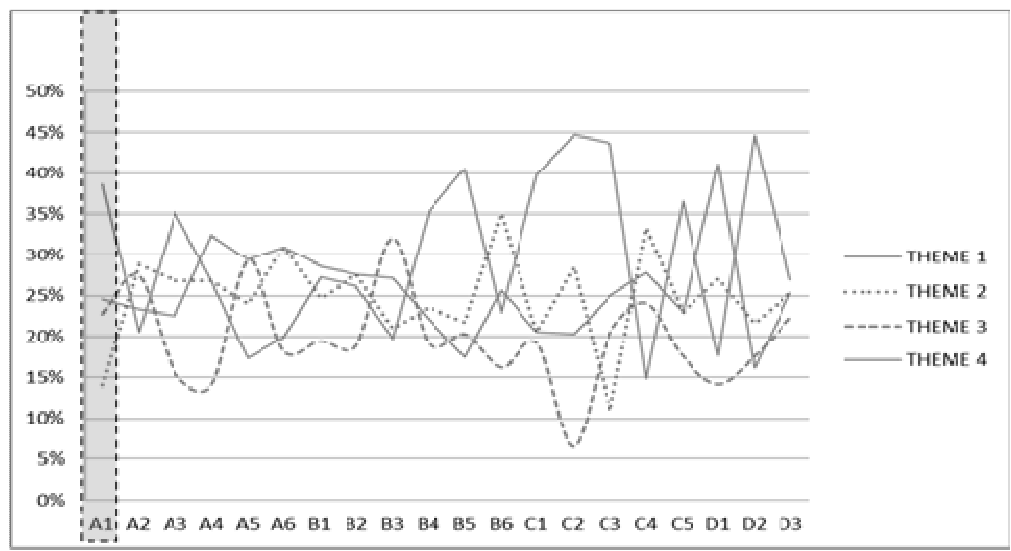

Figure 5: POPC weighed theme. Source: Fascia (2015). 
Utilizing a POPC lens to understand the context of interview transcripts allowed both identification and delineation of natural knowledge interpretation in a transfer scenario. As a consequence of this approach, personal views and associations to knowledge and knowledge transfer scenarios emerged as distinct dyadic phenomena. A POPC omphalos, therefore allowed the study to individualize personal understandings of the contributors to the transfer mechanisms from their own unique world view. Discussions and contradictions emerged independently from any meaning forming activity. In this way, analysis became more meaningful as it uncovered an interpretative personal perspective, from a unique and individual perspective, in doing so, the POPC weight of the actor become the emergent entity. As is evident from the previous examination of perspectives, most, if not all of current knowledge transfer theories and models have emerged from a simplistic idea of collaboration and communication between a source and a receiver. This is based on an idea that was originally introduced by (Shannon and Weaver, 1949) as a mathematical and scientific approach to communication and information and provides little in the way of determining effectiveness or efficiency. Although standard data analysis methods allow data interpretation to elicit overtures of definition, such analysis often dilutes the importance of personalized anomalies as problematic situations and daily remedial actions or discussions. Without the dimension of POPC, perspective association to knowledge transfer within boundaries and parameters personal to the individual and relative to the social group would have remained difficult to ascertain. Therefore, the overarching dimension of a POPC lens, permitted significant and detailed analysis to be completed and allow definitive answers to the proposed questions to emerge.

Q1: Does this business follow traditional business models to underpin success and competitive advantage, despite there being no evidence to suggest this.

Thus, before any knowledge transfer can take place, in the context of an organizational structure, the definitive structure must exist and exhibit boundaries and parameters in which the transfer will initiate. As such, figure 6 shows that the supporting mechanism for knowledge transfer with this participant group is the consideration of ontological and associated epistemological relevance of a deific unanimity.

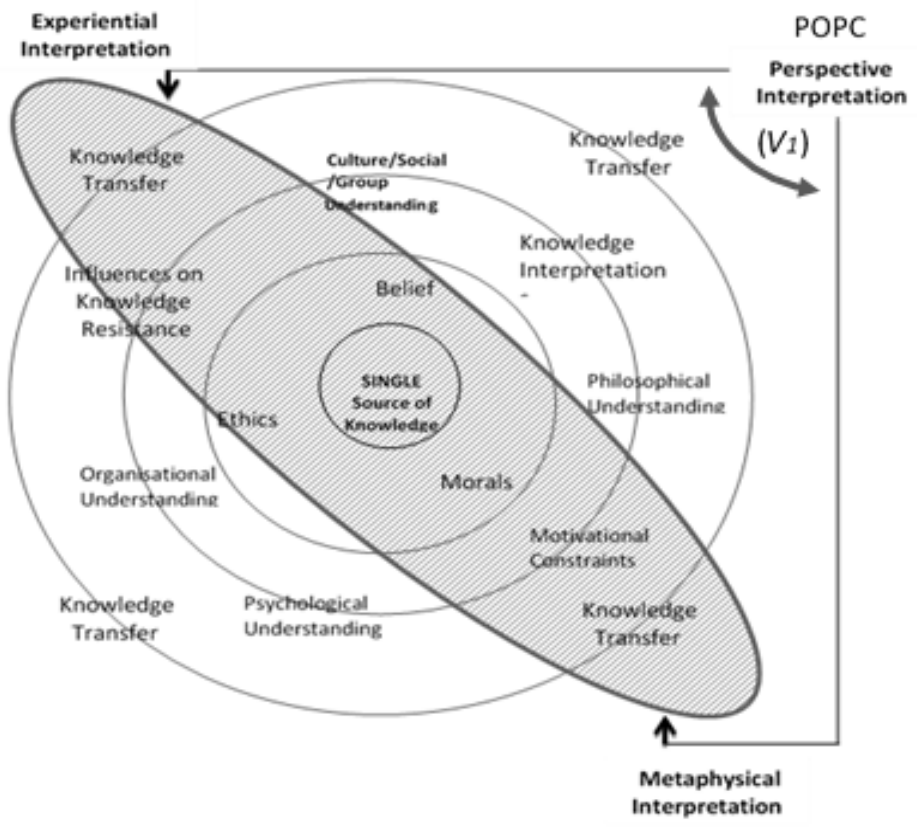


In this way, each actor can rely on a unique combination of knowledge, which is drawn from experience of beliefs and values, the means by which the valuation of this context dependent information is transferred has to be made transparent throughout the whole process of deliberative knowledge transfer. In this way, perceptively effective knowledge transfer in the light of complexity, uncertainty and ambivalence, entails more than the movement of information from one actor to the other. In effect, for these actors, this situation could be considered a Modus Ponens situation of belief regarding the origin and authenticity attached to the knowledge. Additionally, actors are indifferent to other ontological perspectives and adopt a singular view to the interpretation and construct of useful knowledge which may indeed not be interceded by democratically ambivalent, occidental philosophies, politics and law, in fact, quite the reverse.

Q2: Is knowledge transfer able to be identified and encompass a measurement boundary.

For this group, a singular ideological position appears to be a defining factor in the interpretation of knowledge, and therefore, must be considered as a constituent part of each individual's epistemological position from which to understand and assess the effectiveness of the completed knowledge transfer.

As a result, for these actors, knowledge has no formal resistance in terms of philosophical caveat, as there is an accepted singular source of the knowledge, based on experience, with no start or end point. For this group, findings indicated that it is the interpretation of knowledge which defines the actors perspective. In this case, the dichotomy is that theory defines a situation where we cannot posit from a position of singular inference, particularly regarding religion as a caveat for shaping reality experience on a daily basis. However, for this group of actors, it is clearly a defining factor for interpretation of the phenomenon of knowledge, and therefore must be an implicit part of an individual's cognisant base from which to posit from. Interestingly, actors make no attempt at propositional justification, indeed feel that none is required to overarch the transfer.

Thus, for these actors, interpretation of the knowledge experience is directly related to purely explicit reasoning, however, the metaphysical interpretation is dependent on the experience of interpretation surrounding actors alignment to a codified belief system. Therefore, validity of and measurement of success is deduced from, but not a pre requisite of, metaphysical establishment.

\section{CONCLUSION}

This discussion outlined current and historical knowledge philosophy, theory and positioning, but at the same time, placed it within the realms of a business context. The aim of the study was to elicit understanding surround the dimension actors attach to knowledge transfer scenario and relate this to the epistemic principal of knowledge, as current literature disseminates it.

The findings indicated that the epistemic principal of knowledge is important for these participants who recognized the usefulness of moving knowledge from one place to another. Moreover, when conceiving as a faculty for distinguishing between truth and falsity, any judgment that would lack the universally acknowledged value status, traditionally ascribed to them, would be considered false. This predetermined disposition to justified true belief in the knowledge involved within a transfer scenario precluded the ability to empirically discuss alternative relationships that co-existed with experience, and which interact and develop the knowledge understanding as part of the transfer process.

Although a conclusive establishment of a natural boundary to the transfer scenario to exist within was difficult quantify, the transfer experience as defined within this discussion is open to interpretation, and for this group, interpretation serves the purpose of transmitting principles and associations of permanent value.

Nonetheless, such an interpretation of definitive moral order under the premise of justified believe in a priori principles, clearly serve to reinforce an association of interpretation backed only by religious belief. Thus, turning relativistic overtures into sceptical abstractions and inattentiveness to circumstance. Even so, we can conclude that knowledge of any description is transferred, and imparted, not as a result of a predetermined thought process of logic and reason, as is commonly elaborated on by many authors, but as a submissive obedience and 
obligation from a religious standpoint. Consequently, its success is gauged on the interpretation of this complex interchange and evaluated by interaction.

Therefore, for this study, we can conclude that personal experience, in one shape or form, has a fundamental role to play in the phenomenon of knowledge, its conception, its generation and its ultimate transfer mechanisms analysis, but perhaps not as straightforwardly as we would have imagined from current literature. We can also conclude that the outcome would have proved difficult to ascertain without the implementation of a POPC lens of dimension.

\section{REFERENCES}

Alavi, M. and Leidner, D. E. (2001). Knowledge Management and Knowledge Management Systems: Conceptual Foundations and Research Issues. MIS Quar - Terly, 25 (1), pp. 107-136.

Alvesson, M. and Kärreman, D. (2001). Odd Couple: Making Sense of the Curious Concept of Knowledge Management. Journal of Management Studies, 38 (7), pp. 995-1018.

Andrews, K. M. and Delahaye, B. L. (2000). Influences on Knowledge Processes in Organizational Learning: The Psychological Filter. Journal of Management Studies, 37 (6), pp. 797-810.

Ardichvili, A., Maurer, M., Li, W., Wentling, T. and Studemann, R. (2006). Cultural Influence on Knowledge Sharing through Online Communities of Practice. Journal of Knowledge Management, 10 (1), pp. 94-107.

Argote, L. and Ingram, P. (2000). Knowledge Transfer: A Basis for Competitive Advantage in Firms. Organizational Behavior and Human Decision Processes, 82 (1), pp. 150-169.

Audi, R. (1999). The Cambridge Dictionary of Philosophy, 2nd ed., Cambridge: Cambridge University Press. p. 377

Audi, R. (2003). Epistemology: A Contemporary Introduction to the Theory of Knowledge, Routledge.

Barney, J. B. (1991). Firm Resources and Sustained Competitive Advantage. Journal of Management, 17 (1), pp. 99-120.

Berg, B. L. (1995). Qualitative Research Methods for the Social Sciences, 2 nd ed., Alley and Bacon.

Berger, J. M., Fisek, H., Norman, R. Z. and Zelditch, M. (1977). Status Characteristics and Social Interaction: An Expectation-States Approach, New York: Elsevier.

Berger, P. L. and Luckmann, T. (1966). The Social Construction of Reality: A Treatise on the Sociology of Knowledge, New York, NY: Anchor Books.
Berkeley, G. (1710). A Treatise Concerning the Principles of Human Knowledge, Part I.

Blackburn, S. (1995). Objectivism and Projectivism, in J. Kim and E. Sosa (Eds.) A Companion to Metaphysics, Blackwell, Oxford, pp. 368-369.

BonJour, L. and Sosa, E. (2003). Epistemic Justification: Internalism vs. Externalism, Foundations vs. Virtues, Malden, MA: Blackwell.

Brown, J. S. and Duguid, P. (1998). Organizing Knowledge. California Management Review, 40 (3), pp. 90-112.

Brown, J. S. and Duguid, P. (2000). The Social Life of Information, Boston: Harvard Business School Press.

Brown, J. S. and Duguid, P. (2001). Knowledge and Organization: A Social-Practice Perspective. Organization Science, 12 (2), pp. 198-213.

Coleman, J. (1958). Relational Analysis: The Study of Social Organizations with Survey Methods. Human Organization, 17 (4), pp. 28-36.

Cresswell, J. W. (2006). Qualitative Inquiry and Research Design: Choosing among Five Approaches, Sage, Thousand Oaks, CA,

Descartes (1644). Principia philosophiae (Principles of Philosophy; 1641. Meditationes de Prima Philosophia (Meditations on First Philosophy).

Dirks, K. T. and Ferrin, D. L. (2001). The Role of Trust in OrganiZational Settings. Organization Science, 12 (4), pp. 450-467.

Dyer, J. H. and Hatch, N. (2006). Relation-Specific Capabilities and Barriers to Knowledge Transfers: Creating Advantage through Network Relationships. Strategic Management Journal, 27 (8), pp. 701-719.

Fascia, M. (2015). A Unique Investigation of Knowledge Transfer Practices within the Muslim Business Community in Edinburgh. Management Studies and Economic Systems (MSES), 1 (4), pp. 1-19.

Felin, T. and Hesterly, W. S. (2007). The KnowledgeBased View, Nested Heterogeneity, and New Value Creation: Philosophical Considerations on The Locus of Knowledge. Academy of Management Review, 32 (1), pp. 195 - 218.

Ford, D. and Chan, F. (2003). Knowledge Sharing in a Multi-Cultural Setting: A Case Study. Knowledge Management Research and Practice, 1, pp.11-27.

Foucault, M. (1980). Power/Knowledge: Selected Interviews and Other Writings 1972-1977, New York: Pantheon.

Frost, T. S. and Zhou, C. (2005). R\&D Co-Practice and 'Reverse' Knowledge Integration in Multinational Firms. Journal of International Business Studies, 36, pp. 676 - 687.

Grant, R. M. (1996). Toward a Knowledge-Based Theory of the Firm. Strategic Management Journal, 17 (S2), pp.109- 122.

Gupta, A. K. and Govindarajan, V. (2000). Knowledge Management's Social Dimension: 
Lessons from Nucor Steel. Sloan Management Review, 42 (1), pp. 71-80.

Hall, E. T. (1990). Understanding Cultural Differences, London: Intercultural Press.

Hampden-Turner, C. and Trompenaars, F. (2000). Building Cross - Cultural Competence, New Haven, CT: Yale University Press.

Hansen, M. T. (2002). Knowledge Networks: Explaining Effective Knowledge Sharing in Multiunit Companies. Organization Science, 13 (3), pp. $232-248$.

Hansen, M. T., Mors, M. L. and Lovas, B. (2005). Knowledge Sharing in Organizations: Multiple Networks, Multiple Phases. Academy of Management Journal, 48 (5), pp. 776-793.

Hansen, M. T., Nohria, N. and Tierney, T. (1999). What's Your Strategy for Managing Knowledge? Harvard Business Review, 77 (2), pp. 106-116.

Holden, N. (2001). Knowledge Management: Raising the Spectre of the Cross-cultural Dimension. Knowledge and Process Management, 8 (3), pp. 155-63.

Inkpen, A. C. and Tsang, E. W. K. (2005). Social Capital, Networks, and Knowledge Transfer. Academy of Management Review, 30 (1), pp. 146-65.

Jaw, B.-S., Ling, J.-H., Yu-Ping Wang, Ch., Chang, W.-Ch. (2007). The Impact of Culture on Chinese Employees' Work Value. Personnel Review, 36 (5), pp. 763-80.

Klein, P. D. (1999). Human Knowledge and the Infinite Regress of Reasons. Philosophical Perspectives, 13 (S3), pp. 297-325.

Jensen, R. and Szulanski, G. (2004). Stickiness and the Adaptation of Organizational Practices in CrossBorder Knowledge Transfers. Journal of International Business Studies, 35, pp. 508-523.

Lam, A. (2000). Tacit Knowledge, Organizational Learning and Societal Institutions: An Integrated Framework. Organizational Studies, 21 (3), pp. 487-513.

Leibniz (1673). Confessio Philosophi (A Philosopher's Creed); 1703. Explication de l'Arithmétique Binaire (Explanation of Binary Arithmetic); Gerhardt, Mathematical Writings VII. 223; 1710. Théodicée; 1714, Monadologie.

Lemos, N. M. (2007). An Introduction to the Theory of Knowledge, Cambridge University Press.

Lindkvist, L. (2005). Knowledge Communities and Knowledge Collectivities: A Typology of Knowledge Work in Groups. Journal of Management Studies, 42 (6), pp. 1189-1210.

Lou, A. (2010). Empathy in the Context of Philosophy, Palgrave Macmillan, p. 20

March, J. G. (1991). Exploration and Exploitation in Organizational Learning. Organization Science, 2 (1), pp. 71-87.

Mason, J. (2002). Qualitative Researching, 2nd ed., SAGE Publications.
Michailova, S. and Hutchings, K. (2006). National Cultural Influences on Knowledge Sharing: A Comparison of China and Russia. Journal of Management Studies, 43 (3), pp. 383-405.

Mitton, C., Adair, C., McKensie, E., Patten, S. B. and Perry, B. W. (2007). Knowledge Transfer and Exchange: Review and Synthesis of the Literature. Milbank Quarterly, 85 (4), pp. 729-768.

Nonaka, I. (1994). A Dynamic Theory of Organizational Knowledge Creation. Organization Science, 5 (1), pp. 14-37.

Nonaka, I. and Takeuchi, H. (1995). The Knowledge Creating Company, Oxford: OUP.

Nonaka, I., von Krogh, G., Voelpel, S. (2006). Organizational Knowledge Creation Theory: Evolutionary Paths and Future Advances. Organization Studies, 27 (8), pp. 1179-208.

Okhuysen, G. A. and Eisenhardt, K. M. (2002). Integrating Knowledge in Groups: How Formal Interventions Enable Flexibility. Organization Science, 13 (4), pp. 370-386.

Osterloh, M. and Frey, B. S. (2000). Motivation, Knowledge Transfer, and Organizational Forms. Organization Science, 11 (5), pp. 538-550.

Pfeffer, J. (1981). Power in Organizations, Marshfield, MA: Pitman.

Prahalad, C. K. and Doz, Y. L. (1987). The Multinational Mission: Balancing Local Demands and Global Vision, New York: Free Press.

Penrose, E. T. (1959). The Theory of the Growth of the Firm, New York: Wiley.

Polanyi, M. (1962). Personal Knowledge, Chicago: University of Chicago Press.

Polanyi, M. (1966). The Tacit Dimension, New York: Garden City.

Polanyi, M. (1967). The Tacit Dimension, New York: Anchor Books: Garden City.

Reed. R. and DeFillippi, R. J. (1990). Causal Ambiguity, Barriers to Imitation, and Sustainable Competitive Advantage. Academy of Management Review, 15 (1), pp. 88-102.

Schultze, U. and Stabell, C. (2004). Knowing What You Don't Know? Discourses and Contradictions in Knowledge Management Research. Journal of Management Studies, 41 (4), pp. 549-573.

Siau, K., Fui-Hoon Nah, F., Ling, M. (2007). National Culture and Its Effect on Knowledge Communication in Online Virtual Communities. International Electronic Business, 5 (5), pp. 518-532.

Spender, J. C. (1996). Making Knowledge the Basis of a Dynamic Theory of the Firm. Strategic Management Journal, 17 (S2), pp. 45-62.

Szulanski, G. (1996). Exploring Internal Stickiness: Impediments to the Transfer of Best Practice within the Firm. Strategic Management Journal, 17 (S2), pp. $27-43$.

Szulanski, G. (2000). The Process of Knowledge Transfer: A Diachronic Analysis of Stickiness. 
Organizational Behavior and Human Decision Processes, 82 (1), pp. 9-27.

Szulanski, G. and Winter, S. (2002). Getting It Right the Second Time. Harvard Business Review, 62-69.

Szulanski, G., Cappetta, R. and Jensen, R. J. (2004). When and How Trustworthiness Matters: Knowledge Transfer and Moderating Effect of Causal Ambiguity. Organization Science, 15 (5), pp. 600-613.

Szulanski, G. and Jensen, R. J. (2004). Overcoming Stickiness: An Empirical Investigation of the Role of the Template in the Replication of Organizational Routines. Managerial and Decision Economics, 25 (6/7), pp. 347-363.

Tallman, S., Jenkins, M., Henry, N. and Pinch, S. (2004). Knowledge, Clusters, and Competitive Advantage. Academy of Management Review, 29 (2), pp. 258-271.

Trompenaars, F. and Hampden-Turner, C. (1997). Riding the Waves of Culture: Understanding Diversity in Global Business, London: McGraw-Hill.

Tsoukas, H. and Vladimorou, E. (2001). What Is Organizational Knowledge? Journal of Management Studies, 38 (7), pp. 973-993.

Von Hippel, E. (1994). Sticky Information and the Locus of Problem Solving: Implications for Innovation. Management Science, 40 (4), pp. 429-439.

Von Krogh, G., Ichijo, K. and Nonaka, I. (2000). Enabling Knowledge Creation, New York: Oxford University Press USA.

Watson, S. and Hewett, K. (2006). A Multi-Theoretical Model of Knowledge Transfer in Organizations: Determinants of Knowledge Contribution and Knowledge Reuse. Journal of Management Studies, 43 (2), pp. 141-173.

Winter, S. G. (2000). The Satisfying Principle in Capability Learning. Strategic Management Journal, 21, pp. 981-996.

Winter, S. G. and Szulanski, G. (2001). Replication as Strategy. Organization Science, 12 (6), pp. 730-743. 